\title{
Formulation and Development of Famotidine Solid Dispersion Tablets for their Solubility Enhancement
}

\author{
Shirsath Nitin Rajendra ${ }^{1, *}$, Jagtap Vaibhavkumar ${ }^{2}$, Goswami Ajaygiri Kamalgiri ${ }^{1}$ \\ ${ }^{1}$ University Institute of Chemical Technology (UICT), Kavayitri Bahinabai Chaudhari North Maharashtra University (KBCNMU), Jalgaon, \\ Maharashtra, INDIA. \\ ${ }^{2}$ A.R. Ajmera College of Pharmacy, Nagaon, Dhule, Maharashtra, INDIA.
}

\begin{abstract}
Background: Famotidine is BCS class II drug having a low aqueous solubility and low oral bioavailability. It needs to develop into its novel form for solubility and dissolution rate enhancement. Materials and Methods: The aim of the current work was to formulate famotidine (FAM)-poloxamer 188 solid dispersions (SDs) by kneading method for solubility enhancement. The problems of low solubility were eliminated by preparing the SDs using the poloxamer 188 as hydrophilic carrier. Results and Conclusion: The prepared tablets of SDs were characterized by employing solubility, FTIR, disintegration test, friability, wetting time and in-vitro drug release. The optimum values of solubility and in-vitro drug release of prepared novel formulation were maximum than conventional dosage form. The famotidine (FAM)-poloxamer 188 solid dispersions were successfully prepared and seem to be promising for enhanced dissolution rate (solubility) and oral bioavailability.
\end{abstract}

Key words: Solid dispersions (SDs), Kneading method, Famotidine, Solubility, Dissolution rate, Bioavailability.

\section{INTRODUCTION}

Solubility is a major physicochemical factor which affecting absorption/onset of action of drug and its therapeutic potency. If drug having poorly aqueous solubility they may face problem in dosage form design as well as effective therapeutic action. The low dissolution rate and aqueous solubility of drug candidate affects the oral bioavailability of drug. The enhancement of the solubility and dissolution rate of drugs is one of the major factors which affect in development of dosage form. Several methods have been employed to eliminate the problem of poor solubility. ${ }^{1}$

Problems of solubility and dissolution rate of poorly soluble drugs involved various methods are available such as liquisolid, in which drug molecules is adsorbed over or loaded into inert carrier's molecules. ${ }^{2}$ Various surfactants of different charges also helpful in improve wettability and solubility of various hydrophobic drug formulations. ${ }^{3}$ Another approach i.e. drug micronization is unsuitable method because product after micronization has been agglomerated. The solid dispersion is also one of the methods to formulate solid dispersions because of its more effective, simplicity of preparation, not require expensive instruments and ease of optimization. ${ }^{4}$ In solid dispersion techniques, whereby the active moiety were dispersed in a inert carrier molecules or polymer, usually with a view to enhancing solubility, dissolution rate and oral bioavailability. ${ }^{5}$ Famotidine is a thiazole ring containing compound which act tightly on $\mathrm{H}_{2}$ receptors and reduced acid secretion. Famotidine is categories in biopharmaceutical BCS II drug having a low solubility and high permeability and it protect mucosal acid secretions for 10-12 hrs then metabolized and elimination by renal route. ${ }^{6,7}$ Famotidine also decrease both basal, foodstimulated acid secretion by $90 \%$ as well as promotes healing of duodenal ulcer. ${ }^{8}$
Submission Date: 25-07-2019; Revision Date: 04-09-2019; Accepted Date: 03-10-2019.

DOI: 10.5530/ijper.53.4s.149 Correspondence: Shirsath Nitin Rajendra, M.Pham

University Institute of Chemical Technology (UICT), KBC North Maharashtra University, Jalgaon-425001, INDIA.

Phone: +91 7385586065 E-mail: nitin.shirsath.5293@ gmail.com

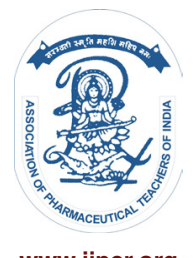

www.ijper.org 
This drug is BCS class II drug having low solubility. Therefore, it needs to formulate into its novel form for solubility enhancement. ${ }^{9}$ In this study, novel SDs was prepared using poloxamer 188 as hydrophilic carrier. The dissolution rates of drug from SDs formulation were investigated in phosphate buffer $\mathrm{pH}-7.4$. The aim this work was to design, prepare and evaluate solid dispersions (SDs) tablet of famotidine (FAM) and poloxamer 188 using kneading method for solubility enhancement of famotidine.

\section{MATERIALS AND METHODS}

\section{Materials}

The active API famotidine (FAM) was obtained as a gift sample from Milan Pharmaceuticals Ltd., Navi Mumbai. Poloxamer 188 was purchased from Alembic pharmaceutical Pvt. Ltd. Badodara. Lactose, Polyvinyl Pyrollidone, Magnesium stearate and Sodium Starch glycolate were purchased from Loba Chemie Pvt Ltd, Mumbai, India respectively. All other chemicals and reagents were of analytical grade and used as provided.

\section{Methods}

\section{Preparation of the Solid dispersion (SDs)}

The Kneading method (KM) was used for the preparation of solid dispersion. Six different batches containing different drugs: carriers (F1-F6) ratio was used for preparation solid dispersion. Famotidine and poloxamer 188 were weighed according to weighed ratios given in Table 1. The famotidine and poloxamer 188 were triturated using a small volume of isopropyl alcohol to give a thick paste, which was kneaded for $30 \mathrm{~min}$ and then dried at $40^{\circ} \mathrm{C}$ in an oven. The dried powder was then pulverized, then passed through mesh no. 30, stored for $48 \mathrm{hrs}$ in a vacuum desiccator packaging in an airtight container. ${ }^{10}$

\section{Saturation solubility studies}

The $5 \mathrm{mg}$ pure famotidine and $5 \mathrm{mg}$ equivalent weight of famotidine containing SDs prepared by kneading method were added separately in conical flask containing $20 \mathrm{ml}$ of distilled. All mixtures were sonicated for 10 min at room temperature and after sonication, shaken for $24 \mathrm{hr}$ at $37 \pm 2^{\circ} \mathrm{C}$ (using orbital shaking incubator, Remi, India). After shaking $5 \mathrm{ml}$ sample aliquots were collected and filtered through Whatman filter paper. The filtrate was analyzed by UV/Visible Spectrophotometer (U-2900, Hitachi, Japan) at 248 nm. ${ }^{11}$

\section{Preparation of Tablets of Solid Dispersions}

Tablets of solid dispersion containing $20 \mathrm{mg}$ equivalent weight of famotidine were prepared by direct compres- sion. The blend of all excipients subjected to compressed on a 10-station rotary tablet punching machine. The composition of tablet is given in Table 2 .

\section{Physical Evaluation of Granules ${ }^{12}$}

\section{Angle of Repose}

The above test was performed for each powder blend by glass funnel method. Weighed the powder sample accurately and passed through the funnel so as to form a heap. The height of funnel was so adjusted that the tip of funnel just touched the apex of the heap. The diameter of the powder cone was measured and the angle of repose was calculated using the following equation.

$$
\operatorname{Tan} \theta=\mathrm{h} / \mathrm{r}
$$

Where, $\mathrm{h}=$ height of cone $\mathrm{r}=$ radius of powder cone

\section{Bulk Density}

About $25 \mathrm{gm}$ of granules pour through a glass funnel into a $100 \mathrm{ml}$ graduated cylinder. The volume of granules occupied the measuring cylinder without compaction was measured and noted $\left(\mathrm{V}_{\curvearrowright}\right)$. Bulk density was calculated as below-

$$
\text { Bulk density }(\mathrm{g} / \mathrm{ml})=\mathrm{M} / \mathrm{Vo}
$$

Where, $\mathrm{M}=$ mass of powder

$\mathrm{V}_{\mathrm{o}}=$ apparent unstirred volume

\section{Tapped Density}

The tapped density was determined as 25 gm solid dispersion granules was poured through a glass funnel into a $100 \mathrm{ml}$ graduated cylinder. The cylinder containing granules was tapped until a constant volume obtained. Volume of granules was occupied after tapping was recorded and tapped density was calculated.

$$
\text { Tapped density }(\mathrm{g} / \mathrm{ml})=\mathrm{M} / \mathrm{V}_{\mathrm{f}}
$$

Where,

$\mathrm{M}=$ weight of sample powder

$$
\mathrm{V}_{\mathrm{f}}=\text { tapped volume }
$$

\section{Compressibility}

The compressibility index was performed by comparing the bulk density and tapped density. A useful empirical guide is given by Carr's Index.

Compressibility Index $=\frac{\text { Tapped density }- \text { Bulk density }}{\text { Tapped density }} \times 100$

\section{Hausner's ratio}

It provides an indication of the degree of densification that could result from vibration of feed hopper. It is another parameter to analyzed flow ability of granules. 
Significant value is suggesting as lower the hausner ratio better is the flowability.

$$
\text { Hausner ratio }=\frac{\text { Tapped density }}{\text { Bulk density }}
$$

\section{Physical characterization of Tablets}

\section{Drug content of tablets formulation}

For drug content analysis, Triturate about $30 \mathrm{mg}$ equivalent weights of tablet and added to $100 \mathrm{ml}$ phosphate buffer $(\mathrm{pH}$ 7.4) in a stoppered conical flasks and mixture were shaken for $30 \mathrm{~min}$. After shaking $5 \mathrm{ml}$ aliquots were withdrawn and filtered using whatman filter paper no 40. The filtrate was analyzed in UV spectrophotometrically at $265 \mathrm{~nm}$.

$$
\text { Drug content }(\%)=\frac{\text { Weight of drug determined }(\mathrm{mg})}{\text { Weight of drug added }(\mathrm{mg}) \times 100}
$$

\section{Weight variation}

Twenty tablets were selected at a random from each formulation and average weight was determined. Then individual tablets were weighed using digital electronic balance and the individual weight was compared with the average weight. The mean $\pm \mathrm{SD}$ (standard deviation) values were calculated. ${ }^{13}$

\section{Hardness or tablet crushing strength (fc)}

Hardness means force in $\mathrm{kg} / \mathrm{cm}^{2}$ or newton needed to break a tablet. Tablets for hardness testing was done using monsanto tablet hardness tester. Randomly five tablets were selected from each batch and subjected to hardness testing by using monsanto hardness tester. The mean values and standard deviation for all the respective batches were calculated.

\section{Friability (F)}

Friability testing of the prepared tablets was conducted using Roche friabilator. The pre-weighted tablets placed in plastic transparent chamber at $25 \mathrm{rpm}$ and rotated for 100 revolutions. Then tablets were de-dusted by using a muslin cloth and weighed again. The friability $(F)$ is obtained by the using formula.

$\mathrm{F}=($ Winitial - Wfinal / Winitial) $\mathrm{x} 100$

\section{In-vitro disintegration time}

The in-vitro disintegration time for all batches was determined using disintegration test apparatus. For testing, each tablets were added in the each tubes of the apparatus and disc was placed on each tube where require. The time needs in seconds for complete disintegration of the tablets was measured.

\section{Wetting time}

Tablet was placed in a petri plate (internal diameter is $6.5 \mathrm{~cm}$ ) having a piece of tissue paper double folded containing $6 \mathrm{ml}$ of water. Then measured time required in seconds for complete wetting. ${ }^{14,15}$

\section{Fourier transforms infra-red spectroscopy}

Drug-polymer compatibility were detected by FTIR spectrophotometer (Shimadzu, FTIR-8400). FTIR study of the pure famotidine and prepared famotidine tablet was carried out by $\mathrm{KBr}$ pellet method. The mixture of sample and $\mathrm{KBr}$ were manual press into a disc in a $\mathrm{KBr}$ press. The spectrum was recorded from range of 4000 to $400 \mathrm{~cm}_{-1} \cdot{ }^{16}$

\section{In-vitro drug release studies}

Dissolution studies for famotidine SDs tablet and pure famotidine were carried out separately using the USP paddle method at $37^{\circ} \mathrm{C}$ in dissolution tester (Electrolab auto-sampler dissolution tester TDT-08L) at $50 \mathrm{rpm}$ with $900 \mathrm{~mL}$ of phosphate buffer $\mathrm{pH}-7.4$ as dissolution media. The weight of SDs equivalent to $30 \mathrm{mg}$ of famotidine and $30 \mathrm{mg}$ pure famotidine were filled into the hard gelatin capsules separately and then exposed to the dissolution media separately for $2 \mathrm{hrs}$. The samples were collected at predetermined time (i.e.10, 20, 30, 45, 60, 90 and $120 \mathrm{~min}$ ) and then filtered using a whatman filter paper. In order to maintain the sink condition $5 \mathrm{ml}$ fresh medium was added after each $5 \mathrm{ml}$ sample collection and filtrate was analyzed by UV spectrophotometer at $265 \mathrm{~nm} \cdot{ }^{17,18}$

\section{RESULTS AND DISCUSSIONS}

The saturation solubility of famotidine in distilled water and phosphate buffer $\mathrm{pH} 7.4$ were $0.0066 \mathrm{mg} / \mathrm{L}$ and $0.0075 \mathrm{mg} / \mathrm{L}$ respectively. The prepared granules were subjected for characterizations and the results are given in the Table 3. The compressed tablets of SDs were analysed for physical properties and tabulated in Table 4. The drug content of tablets formulations were in range of 64.14 to $92.33 \%$ for all experimental run. The hardness of prepared formulation were in range of 3.60 $\mathrm{kg} / \mathrm{cm}^{2}$ to $4.0 \mathrm{~kg} / \mathrm{cm}^{2}$ for all six batches and in case of hardness of marketed formulation was about 4.053.60 $\mathrm{kg} / \mathrm{cm}^{2}$. The uniformity of weight of all prepared formulation was in range of $188 \mathrm{mg}$ to $205 \mathrm{mg}$. The \% friability of all $\mathrm{F} 1$ to $\mathrm{F} 6$ formulations were in ranges of $0.53 \%$ to $0.77 \%$ and the $\%$ friability of marketed formulation was about $0.7 \%$. The wetting time for all six formulations and marketed formulation were in range of 45-59 sec and $63 \mathrm{sec}$ respectively. The disintegration 


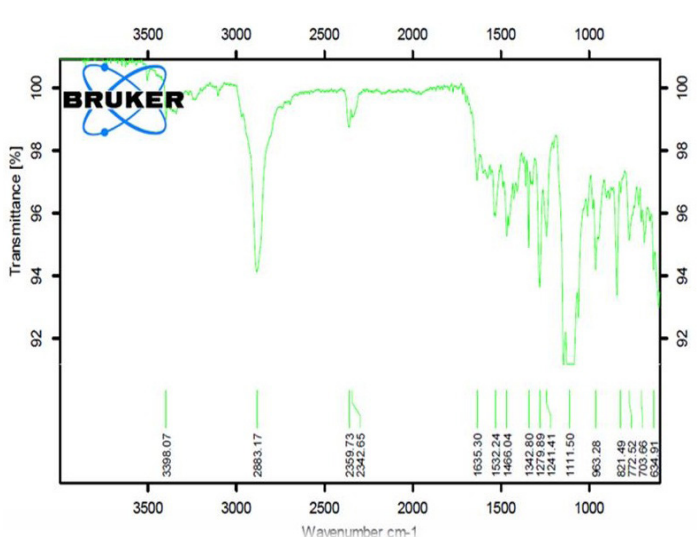

Figure 1(a): FTIR spectra of pure famotidine.

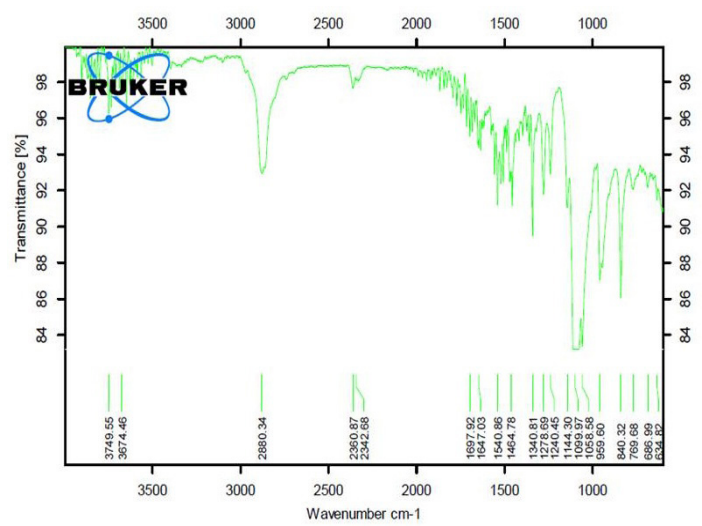

Figure 1(b): FTIR spectra of famotidine + Poloxamer 188.

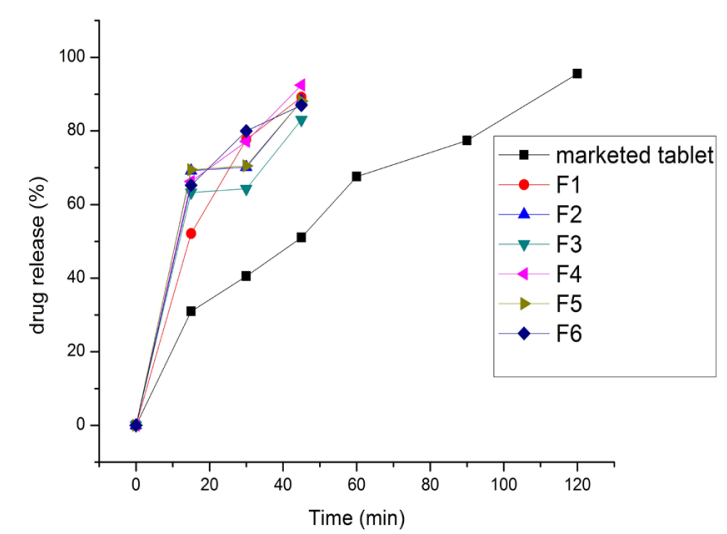

Figure 2: Dissolution profiles of all six prepared famotidine formulation and marketed famotidine tablet.

\begin{tabular}{|c|c|c|}
\hline \multicolumn{3}{|c|}{ Table 1: Drug- polymer proportion } \\
\hline Code & Solid Dispersion & Drug: Polymer \\
\hline F1 & Famotidine : Poloxamer 188 & $1: 1$ \\
\hline F2 & Famotidine : Poloxamer 188 & $1: 2$ \\
\hline F3 & Famotidine : Poloxamer 188 & $1: 3$ \\
\hline F4 & Famotidine : Poloxamer 188 & $1: 4$ \\
\hline F5 & Famotidine : Poloxamer 188 & $1: 5$ \\
\hline F6 & Famotidine : Poloxamer 188 & $1: 6$ \\
\hline
\end{tabular}

\section{Table 2: Composition of tablets of solid dispersions}

\begin{tabular}{|c|c|}
\hline Ingredients & Formulation $\mathbf{( m g )}$ \\
\hline Solid dispersion is equivalent to $20 \mathrm{mg}$ & 120 \\
\hline Starch & 10 \\
\hline Lactose & 168.8 \\
\hline Talc & 1 \\
\hline Magnesium stearate & 0.2 \\
\hline
\end{tabular}

\section{Table 3: Pre-compressed parameter for granules}

\begin{tabular}{|c|c|}
\hline Parameters & Results \\
\hline Angle of Repose $(\theta)$ & 26.71 \\
\hline Bulk Density $(\mathrm{g} / \mathrm{ml})$ & 0.472 \\
\hline Tapped Density $(\mathrm{g} / \mathrm{ml})$ & 0.566 \\
\hline$\%$ Compressibility & 15.1 \\
\hline Hausner Ratio & 1.184 \\
\hline
\end{tabular}

time of all F1-F6 batches were in range of $3.25 \mathrm{~min}$ to $4.27 \mathrm{~min}$. The FTIR spectra of pure famotidine Figure 1(a) shows major peaks in $3398 \mathrm{~cm}^{-1}(\mathrm{~N}-\mathrm{H}), 2883 \mathrm{~cm}^{-1}$, $2359 \mathrm{~cm}^{-1}(\mathrm{C}-\mathrm{H}), 2342 \mathrm{~cm}^{-1}(\mathrm{C}-\mathrm{H}), 1636 \mathrm{~cm}^{-1}, 1535 \mathrm{~cm}^{-1}$ $(\mathrm{N}=\mathrm{O})$ and $1466 \mathrm{~cm}^{-1}(\mathrm{~N}=\mathrm{O})$. And FTIR spectra of prepared tablets formulation Figure 1(b) shows characteristic peaks in $3674 \mathrm{~cm}^{-1}(\mathrm{O}-\mathrm{H}), 2880 \mathrm{~cm}^{-1}(\mathrm{C}-\mathrm{H})$, $2342 \mathrm{~cm}^{-1}(\mathrm{O}=\mathrm{C}=\mathrm{O}), 1697 \mathrm{~cm}^{-1}(\mathrm{C}=\mathrm{O})$ and $1647 \mathrm{~cm}^{-1}$ $(\mathrm{C}=\mathrm{C})$. From the FTIR studies, we conclude that there is no major interaction between drug and polymer. The in vitro release of marketed formulation was about 95.57 $\%$ in 120 min and all prepared formulation released the drug in range of 82.91 to $92.45 \%$ of drug in 45 min see Figure 2. It concludes that, dissolution profile of pre-

\begin{tabular}{|c|c|c|c|c|c|c|c|}
\hline \multicolumn{8}{|c|}{ Table 4: Post Compression Evaluation of Marketed \& Formulated Tablet } \\
\hline Parameters & F1 & F2 & F3 & F4 & F5 & F6 & $\begin{array}{c}\text { Marketed } \\
\text { Tablet }\end{array}$ \\
\hline Weight Uniformity (mg) & 198 & 196 & 188 & 205 & 199 & 192 & 199.60 \\
\hline Drug content of tablets(\%) & 64.14 & 80.77 & 92.33 & 75.36 & 69.74 & 77.96 & 96.45 \\
\hline DT (min) & 4.04 & 3.30 & 3.53 & 3.25 & 4.25 & 4.14 & 4.11 \\
\hline Friability (\%) & $0.61 \%$ & $0.77 \%$ & $0.53 \%$ & $0.66 \%$ & $0.75 \%$ & $0.69 \%$ & $0.7 \%$ \\
\hline Hardness (kg/cm $\left.{ }^{2}\right)$ & 3.8 & 3.6 & 3.7 & 3.8 & 4.0 & 3.7 & 4.05 \\
\hline Wetting time (sec) & 59 & 55 & 45 & 59 & 54 & 48 & 63 \\
\hline
\end{tabular}


pared formulation was increased with respect to marketed formulation.

\section{CONCLUSION}

In the present study, famotidine- poloxamer 188 Solid Dispersions (SDs) by kneading technique was successfully prepared. The results of solubility testing and in vitro dissolution studies conclude that, the prepared tablet of solid dispersion shows higher solubility that marketed formulation. Increased in solubility and dissolution rate of SDs occur due to the decreased in particle size, increased in surface area and increased wettability of drug because complex with hydrophilic carrier. SDs of famotidine developed by kneading method may represent a promising approach for solubility enhancement.

\section{ACKNOWLEDGEMENT}

We are very much thankful to TEQIP-III for providing financial support to carry out this research work. We are also thankful to Milan Lab. Pvt. Ltd., Navi Mumbai, India, for providing the gift sample of famotidine.

\section{CONFLICT OF INTEREST}

The authors report no conflicts of interest. The authors alone are responsible for the content and writing of this article.

\section{ABBREVIATIONS}

BCS: Biopharmaceutics classification of drug; FAM: Famotidine; SDs: Solid dispersions; KM: Kneading method; FTIR: Fourier transform infrared spectroscopy; KBr: Potassium bromide.

\section{REFERENCES}

1. Dressman J, Leuner C. Improving drug solubility for oral delivery using solid dispersions. European Journal of Pharmaceutical Sciences. 2000:50(1);4760.
2. Nokhodchi A, Javadzadeh Y. et al. The effect of type and concentration of vehicles on the dissolution rate of a poorly soluble drug (indomethacin) from liquisolid compacts. J Pharm Pharm Sci. 2005;8(1):18-25.

3. Bakatselou V, Oppenheim RC, Dressman JB. Solubilization and wetting effects of bile salts on the dissolution of steroids. Pharm Res. 1991;8(12):1461-9.

4. Chiou WL, Reigelman S. Pharmaceutical applications of solid dispersion systems. J Pharm Sci. 1971;60(9):1281-302.

5. Noyes AA, Whitney WR. The rate of solution of solid substances in their own solutions. J Am Chem Soc. 1997;19(12):930-4.

6. Li J, Wang H, Yang B, Xu L, Zheng N, Chen H, et al. Control-release microcapsule of famotidine loaded biomimetic synthesized mesoporous silica nanoparticles : Controlled release effect and enhanced stomach adhesion in vitro. Mater Sci Eng C. 2016;58:273-7.

7. Shafique M, Khan MA, Khan WS, Ahmad W, Khan S. Fabrication , Characterization and in vivo Evaluation of Famotidine Loaded Solid Lipid Nanoparticles for Boosting Oral Bioavailability. Journal of Nanomaterials. 2017;2017:10.

8. Verma U, Naik JB, Mokale VJ. Preparation and Characterisation of the Inclusion Complex of Famotidine Preparation and Characterisation of the Inclusion Complex of Famotidine with ( 2-Hydroxy Propyl ) - B-Cyclodextrin and Pvp K-30 : Effects on Solubility and Bitter Taste Mask. Elsevier Publ. 2014;(10):63-7.

9. Shirsath NR, Goswami AK. Nanocarriers Based Novel Drug Delivery as Effective Drug Delivery: A Review. Current Nanomaterials, 2019;4(2):71-83. DOI : 10.2174/2405461504666190527101436.

10. Verma S, Patel U, Patel RP. Formulation and evaluation of ivermectin solid dispersion. Journal of Drug Delivery and Therapeutics. 2017;7(7):15-7.

11. Hecq J, Deleers M, Fanara D, Vranckx H, Amighi K, et al. Preparation and characterization of nanocrystals for solubility and dissolution rate enhancement of nifedipine. International Journal of Pharmaceutics. ;299(12):167-77

12. Aulton ME. Pharmaceutical; The Science of dosage form design. $2^{\text {nd }}$ edition, London; Churchill Livingstone. 2005.

13. Rakesh $\mathrm{P}$, Mona $\mathrm{P}$, et al. Formulation and evaluation of orally disintegrating tablets: comparison of natural and synthetic superdisintegrant. Scholars Res Library. 2011;3(2):407-18.

14. Nagendrakumar D, Raju SA, et al. Design of fast dissolving granisetron hydrochloride tablets using novel co-processed superdisintegrants. Int J Pharm Sci Rev and Res. 2010;1(1):58-62.

15. Deepak S, Dinesh K, et al. Fast disintegrating tablets: A new era in novel drug delivery system and new market opportunities. J Drug Delivery and Thera. 2012;2(3):74-86

16. Xu W, Xie H, Cao Q, Shi L, Cao Y, Zhu X. Enhanced dissolution and oral bioavailability of valsartan solid dispersions prepared by a freeze- drying technique using hydrophilic polymers Enhanced dissolution and oral bioavailability of valsartan solid dispersions prepared by a freeze-drying techniq. Drug Deliv. 2016;23(1):41-8.

17. Xu WJ, Liu Y, Shi LL, Cui JH, Cao QR. In vitro dissolution and physicochemical characterizations of novel PVP-based solid dispersions containing valsartan prepared by a freeze-drying method. Pakistan Journal of Pharmaceutical Sciences. 2014;27(6):1799-804.

18. Alatas F, Ratih H, Soewandhi SN. Enhancement of solubility and dissolution rate of telmisartan by telmisartan-oxalic acid co-crystal formation. Int J Pharm Pharm Sci. 2015;7(3):423-6.

\section{SUMMARY}

Solubility plays a key role in effective therapeutic action of drugs. Lesser the solubility and dissolution rate of poorly aqueous-soluble drugs leads to lesser efficiency as well as oral bioavailability. For the enhancement of solubility of BCS class II drugs i.e. famotidine, we prepared solid dispersion of famotidine using a kneading method and poloxamer 188 as hydrophilic carrier. The prepared novel formulation were evaluated using different techniques like solubility analysis, FTIR, disintegration test, friability, wetting time and in-vitro drug release. The optimum values of solubility and in-vitro drug release of prepared novel formulation were found maximum than conventional dosage form. From the study, we conclude that, the prepared formulation is improved solubility, dissolution rate and oral bioavailability of famotidine. 


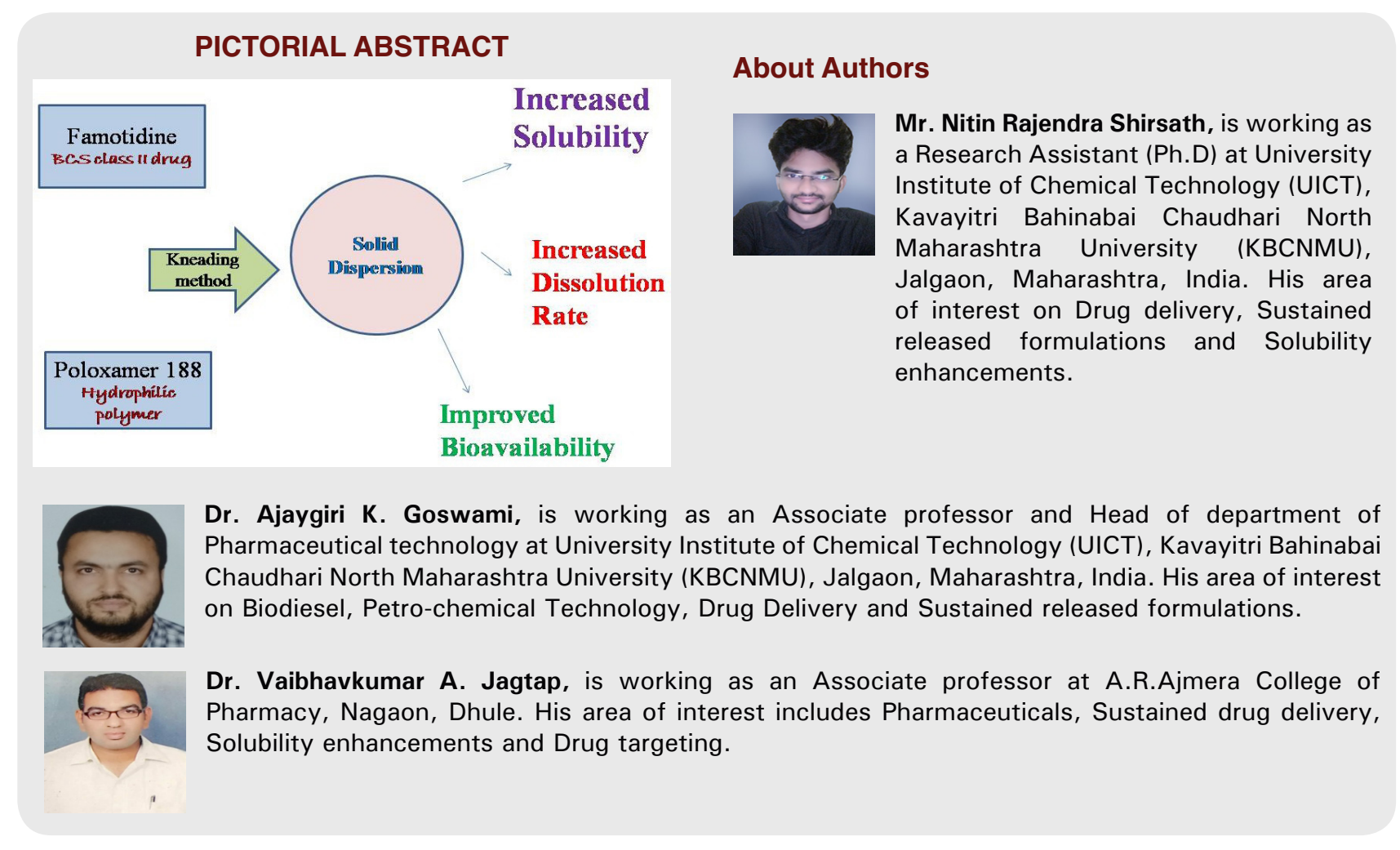

Cite this article: Shirsath NR, Jagtap VA, Goswami AK. Formulation and Development of Famotidine Solid Dispersion Tablets for their Solubility Enhancement. Indian J of Pharmaceutical Education and Research. 2019;53(4s):s548-s53. 